\title{
HOT CORROSION OF NICKEL-BASE ALLOYS IN BIOMASS DERIVED FUEL SIMULATED ATMOSPHERE
}

\author{
C. Leyens ${ }^{1,2}$, I.G. Wright ${ }^{1}$, and B.A. Pint ${ }^{1}$ \\ ${ }^{1}$ Oak Ridge National Laboratory \\ Metals and Ceramics Division \\ Oak Ridge, Tennessee 37831-6156 \\ 2 on leave from: DLR-German Aerospace Center \\ Institute of Materials Research \\ 51170 Cologne, Germany
}

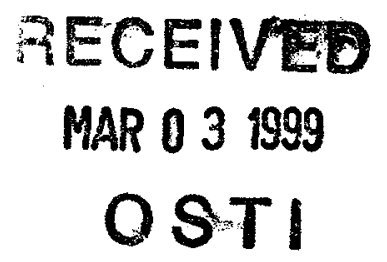

\begin{abstract}
Biomass fuels are considered to be a promising renewable source of energy. However, impurities present in the fuel may cause corrosion problems with the materials used in the hot sections of gas turbines and only limited data are available so far. As part of the Advanced Turbine Systems Program initiated by the U.S. Department of Energy, the present study provides initial data on the hot corrosion resistance of different nickel-base alloys against sodium sulfate-induced corrosion as a baseline, and against salt compositions simulating biomass-derived fuel deposits. Single crystal nickel-superalloy René N5, a cast NiCrAlY alloy, a NiCoCrAIY alloy representing industrially used overlay compositions, and a model $\beta-\mathrm{NiAl}+\mathrm{Hf}$ alloy were tested in $1 \mathrm{~h}$ thermal cycles at $950^{\circ} \mathrm{C}$ with different salt coatings deposited onto the surfaces. Whereas the NiCoCrAlY alloy exhibited reasonable resistance against pure sodium sulfate deposits, the $\mathrm{NiCrAlY}$ alloy and René N5 were attacked severely. Although considered to be an 'ideal' alumina former in air and oxygen at higher temperatures, $\beta-\mathrm{NiAl}+\mathrm{Hf}$ also suffered from rapid corrosion attack at $950^{\circ} \mathrm{C}$ when coated with sodium sulfate. The higher level of potassium present in biomass fuels compared with conventional fuels was addressed by testing a NiCoCrAlY alloy coated with salts of different $\mathrm{K} / \mathrm{Na}$ atomic ratios. Starting at zero $\mathrm{Na}$, the corrosion rate increased considerably when sodium was added to potassium sulfate. In an intermediate region the corrosion rate was initially insensitive to the $\mathrm{K} / \mathrm{Na}$ ratio but accelerated when very Na-rich compositions were deposited. The key driver for corrosion of the NiCoCrAlY alloy was sodium sulfate rather than potassium sulfate, and no simple additive or synergistic effect of combining sodium and potassium was found.
\end{abstract}




\section{Introduction}

\section{General Background}

Fuels derived from peat, forest and agricultural wastes, or from plants grown specifically for their calorific value are of interest as a renewable source of energy for future power generation systems for ecological as well economical reasons. Today biomass provides about $14 \%$ of the energy needs worldwide, thus ranking fourth as an energy resource [1]. It is quite evident that biomass resources offer environmental advantages over many other fossil fuels. If grown and consumed on a sustained-energy basis, biomass feedstocks do not contribute to carbon dioxide enrichment in the atmosphere over their total life cycle. The viability of biomassfueled power generation depends on the ability to sustain the mechanical integrity of the plant, and on the economics of the process. Recent data on the projected economics of a cogeneration system consisting of a biomass gasifier combined with gas turbine power production suggested power costs comparable with those from conventional coal-fired power plants. Therefore, biomass feedstocks are considered to have the potential to contribute significantly to the world's energy mix [1].

In principle, biomass fuels can be utilized directly as solid fuel via simple combustion processes in steam boilers or via more sophisticated routes such as liquefaction or gasification followed by combustion in gas turbines [2]. In order to meet the 60 percent thermal efficiency goal of future electric power plants targeted by DOE's Advanced Turbine Systems (ATS) program [3], conversion of solid biomass to an essentially clean gaseous fuel is necessary. However, the highest efficiency levels achieved in large utility scale systems today are on the order of $58 \%$; so that the possible interaction of biomass-derived fuels with the advanced turbine design features necessary in ATS engines must be considered. For smaller plant sizes (5-20MW), for which the efficiency is generally lower, combined cycle efficiencies up to $42.5 \%$ seem to be feasible using biomass-derived fuels, essentially without any necessity to modify the current gas turbine design [4].

\section{$\underline{\text { Materials Issues }}$}

At the operating temperatures of gas turbines, the hot gas-path components must be capable of forming a thermally grown oxide layer to protect against rapid metal loss due to oxidation. The oxides of $\mathrm{Al}$ and $\mathrm{Cr}$ are the most effective oxidation barriers as they form slow-growing scales, thus keeping the oxidation rate in a technically reasonable range. Therefore all nickel- or cobalt-based superalloys rely on the formation of either alumina or chromia scales. In service, loss of the protective oxide scales by spallation, either induced by growth stresses after reaching a critical scale thickness, or as a result of imposed thermal and mechanical stresses, is a critical factor limiting the useful lifetime of the components. Lost protective scale can be reformed as long as the activity of scaleforming elements in the underlying alloy is higher than some critical level needed for an external protective scale to form. Repeated scale loss and reformation, however, depletes the alloy of these elements such that less-protective scales of the base metal may become dominant, resulting in a rapid increase of the oxidation rate which finally leads to component failure. From an oxidation standpoint, high levels of $\mathrm{Al}$ and/or $\mathrm{Cr}$ are therefore highly desirable. However, the demand of maximum high-temperature strength and creep resistance for superalloys has led to the development of alloys containing relatively low levels of $\mathrm{Al}$ and $\mathrm{Cr}$ (compared with the levels required to form protective scales of exclusively alumina or chromia). Thus, protective coatings are universally used for components in the hot sections of gas turbines; several coating application 


\section{DISCLAIMER}

This report was prepared as an account of work sponsored by an agency of the United States Government. Neither the United States Government nor any agency thereof, nor any of their employees, make any warranty, express or implied, or assumes any legal liability or responsibility for the accuracy, completeness, or usefulness of any information, apparatus, product, or process disclosed, or represents that its use would not infringe privately owned rights. Reference herein to any specific commercial product, process, or service by trade name, trademark, manufacturer, or otherwise does not necessarily constitute or imply its endorsement, recommendation, or favoring by the United States Government or any agency thereof. The views and opinions of authors expressed herein do not necessarily state or reflect those of the United States Government or any agency thereof. 


\section{DISCLAIMER}

Portions of this document may be illegible in electronic image products. Images are produced from the best available original document. 
methods are available [5], the choice depending on performance, application, and cost considerations.

Although alloys used as coatings have been mainly optimized for oxidation and corrosion resistance, the aforementioned rules for superalloys do in principle apply for coatings. Depending on service temperature of the hot gas path components, which can also vary locally on a given blade or vane, fuel quality and environmental conditions under which the turbine operates, the coatings can be degraded by oxidation or by hot corrosion. Hot corrosion is generally defined as the accelerated oxidation of materials [6] caused by ingestion of impurities forming low-melting salts. Certain salts can effectively dissolve the protective oxide scale formed on the components, thus accelerating the consumption of protective scaleforming elements. The relative solubilities of typical protective scales in molten salts such as $\mathrm{Na}_{2} \mathrm{SO}_{4}$ have been well documented [7]. Although alumina and chromia exhibit minimum solubility in molten $\mathrm{Na}_{2} \mathrm{SO}_{4}$ at a similar level of salt basicity, chromia scales are found in practice to be preferable to alumina under hot corrosion conditions. Dissolution of $\mathrm{Al}_{2} \mathrm{O}_{3}$ in the molten salt results in a shift in the basicity of the salt to a region of increased alumina solubility, hence to an acceleration of attack. The reprecipitation of the alumina as finely-divided particles at the outer surface of the melt greatly decreases the chance of reforming a protective alumina scale, and rapid hot corrosion attack ensues. In contrast, the ability of the solutes of $\mathrm{Cr}_{2} \mathrm{O}_{3}\left(\mathrm{NaCrO}_{2} ; \mathrm{Na}_{2} \mathrm{CrO}_{4} ; \mathrm{Cr}\left(\mathrm{SO}_{4}\right)_{1.5}\right.$; and $\left.\mathrm{CrS}\right)$ to support a buffering action, and hence resist large shifts in the basicity of the molten salt, together with the fact that the solubility of $\mathrm{Cr}_{2} \mathrm{O}_{3}$ is higher as $\mathrm{Na}_{2} \mathrm{CrO}_{4}$ (at the external surface) than as $\mathrm{NaCrO}_{2}$ (at the internal surface) means that dissolution of $\mathrm{Cr}_{2} \mathrm{O}_{3}$ is limited, and reprecipitation of the salt film cannot occur, are probably the reasons for the superior performance of chromia-forming alloys in Type I hot corrosion [7].

Impurities which form these aggressive salts or are already present as salts may enter the gas turbine through the air and the fuel. In aeroengines the use of relatively pure fuels and high operating temperatures make hot corrosion less of a concern [8]. However, the ingestion of airborne impurities such as, for example, seasalt aerosols, runway de-icing salts or even sand [9], through the compressor may cause severe erosion problems in the compressor and hot corrosion attack of the turbine. In gas turbines for power generation, the use of lower-grade fuels may be a significant source of impurities. Even when such turbines are operated with clean fuels, the ingestion of airborne impurities (sea, industrial, and agricultural salts) provides the potential for hot corrosion attack. The 'contaminant flux rate', which is the amount of deposits added per surface area, per time, was calculated to be as high as $4 \mathrm{mg} \cdot \mathrm{cm}^{-2} \cdot \mathrm{h}^{-1}$ for an industrial gas turbine burning $6000 \mathrm{~kg} \cdot \mathrm{h}^{-1}$ of fuel with an impurity level of $2 \mathrm{ppm} \mathrm{V}_{2} \mathrm{O}_{5}$ [10]. For coal-derived fuel-fired gas turbines, the overall contaminant flux rate might be as high as $500 \mathrm{mg} \cdot \mathrm{cm}^{-2} \cdot \mathrm{h}^{-1}$ [11]. As the air-to-fuel ratio is typically on the order of 30:1 to 50:1 at full power [12], a relatively low impurity level in the air is amplified relative to the fuel by a factor of 30 to 50 in the turbine. It is therefore quite evident that both the air and the fuels might provide considerable amounts of harmful impurities.

Deposition of salts can occur through condensation of the salts from the vapor phase [13] or by direct particle impingement either in the form of aerosols [14] or larger particles [14, 15]. Whereas in the first case, the supply of salt should be continuous, provided that the temperature of the components is low enough to allow for condensation, a random or sporadic supply is expected in the latter case. Recently, Bornstein and Allen [15] carefully investigated the deposits on compressor and turbine airfoils which were in service in an industrial gas turbine. 
They found that the salt compositions of the first three stages of the turbine were essentially identical. However, for a condensation mechanism, large differences in salt chemistries were expected due to the different thermodynamic conditions in the different stages. The conclusion drawn by these authors was that impaction rather than condensation was the likely predominant deposition mechanism. The main source for the impacting particles was the compressor, where deposits may accumulate and eventually shed in a random or sporadic mode rather than continuously. Furthermore, careful investigations of the salts on the inner surface (cooling channels) and the outer surface of the airfoils revealed that the salt chemistry was nearly identical. As the inner surfaces of the airfoil were not exposed to the combustion gases, it was suggested that the salt compositions were essentially not affected by the combustion environment itself. The main constituent of the deposits was sodium sulfate $\left(\mathrm{Na}_{2} \mathrm{SO}_{4}\right)$. It is remarkable that no chlorides were found on turbine deposits, whereas $\mathrm{MgCl}_{2}$ was present in compressor deposits. The role of chlorine on the hot corrosion of airfoil materials is still considered to be unresolved [6].

Unlike for conventional fuels such as natural gas or even coal-derived fuel gas, knowledge of the corrosion behavior of materials operating in biomass-fuel powered gas turbines is fairly poor. An analysis of the potential corrosion threat to gas turbines materials fueled by biomass-derived gasification products is the subject of a companion paper [12]. Of particular concern is the relatively high alkali (mostly K) content and the relatively low sulfur content of the ash of biomassderived fuels, which is quite different from the composition of deposits typically associated with hot corrosion. The relatively high alkali metal content of biomass feedstock is a further concern as this is a key element in the formation of ultrafine primary particles [16] which may grow and thus cause particle erosion problems. As shown in Table I, the ashes of biomass feedstocks almost always have higher $\mathrm{K} / \mathrm{Na}$ ratios than coal, whereas the $\mathrm{Ca} / \mathrm{Mg}$ ratio is either similar or even lower than that in coal (Table I).

The objective of the present study was to assess the corrosion behavior of a singlecrystal nickel-base superalloy, a model $\beta-\mathrm{NiAl}+\mathrm{Hf}$ aluminide alloy and cast MCrAlY alloys representing overlay coating compositions, in cyclic hot corrosion tests with conventional salt compositions and with modified salts relevant to biomass fuels. In the case of $\beta-\mathrm{NiAl}+\mathrm{Hf}$, which is an 'ideal' alumina scale former in air or oxygen and has a large reservoir of aluminum, it might be expected that, although dissolution of the alumina scale would occur, damage to the alloy would be limited in each deposition event and there would be no great acceleration in the rate of attack. The other alloys contained $\mathrm{Cr}$, so that their relative performance would indicate the level of $\mathrm{Cr}$ required in any alloy expected to see service in conditions where Type I hot corrosion in biomass-derived fuels is possible. The extent of biomass-related hot corrosion attack relative to conventional hot corrosion was studied in thermal cycling tests at $950^{\circ} \mathrm{C}$ and SEM investigations.

Table I: Composition and S content of ashes from various feedstocks [17, 18].

\begin{tabular}{lcccc}
\hline feedstock & $\mathrm{K} / \mathrm{Na}$ & $\mathrm{Ca} / \mathrm{Mg}$ & $(\mathrm{Na}+\mathrm{K}) /(\mathrm{Ca}+\mathrm{Mg})$ & $\mathrm{S}$ (gatoms/kg ash) \\
\hline Illinois \#6 coal & 2.3 & 8.3 & 0.9 & 6.9 \\
peat (fuel) & 1.4 & 6.8 & 0.1 & 1.5 \\
pine bark & 17.0 & 10.7 & 0.2 & 0.6 \\
forest residues & 12.6 & 8.7 & 0.3 & 0.6 \\
wheat straw & 41.0 & 4.8 & 2.5 & 0.0 \\
switchgrass & 139.4 & 1.9 & 2.9 & 0.1 \\
\hline
\end{tabular}




\section{Experimental}

The alloys included in this study included cast versions of NiCrAlY (Ni-10Cr-10Al0.06Y, in wt.\%) and NiCoCrAlY (Ni-22Co-18Cr-12.5Al-0.06Y, in wt.\%) coatings, as well as $\beta-\mathrm{NiAl}+\mathrm{Hf}$. All of the alloys were vacuum induction melted and cast in a water-chilled copper mold. The castings were then annealed at $1300^{\circ} \mathrm{C}$ for $4 \mathrm{~h}$ in quartz ampules. For comparison, a second generation single crystal nickel-base superalloy, René N5, developed by General Electric Aircraft Engines was used. The chemical compositions of the alloys are given in Table II. $\beta$ - NiAl $+\mathrm{Hf}$ was selected as a model alloy in order to assess the corrosion resistance of an 'ideal' alumina former [19]. This alloy was used in the as-cast and annealed, as well as in the as cast, annealed and preoxidized $\left(24 \mathrm{~h}\right.$ at $\left.1200^{\circ} \mathrm{C}\right)$ condition. Specimens $(\varnothing 1.5 \mathrm{~cm} \times 0.1-$ $0.15 \mathrm{~cm}$ ) were cut from the castings and then polished with $\mathrm{SiC}$ paper up to 600 grit, avoiding preferred orientation of the grinding marks. The $1 \mathrm{~h}$ thermal cycles at $950^{\circ} \mathrm{C}$ were performed in an automated test rig in which the specimens were held in a vertical tube furnace by $\mathrm{Pt}-\mathrm{Rh}$ hooks for $1 \mathrm{~h}$ and cooled to room temperature for $10 \mathrm{~min}$ between cycles. Dry oxygen flowed continuously into the bottom of the tube during the exposures. $\mathrm{SO}_{x}$ (of the order of 0.1 vol. percent) usually used in such tests was omitted from these initial tests to simplify operation. Prior to testing all samples were ultrasonically cleaned in acetone and methanol. Except for bare René N5 and $\beta-\mathrm{NiAl}+\mathrm{Hf}$ specimens, all specimens were coated with water solutions of different salt compositions (Table III). The salt solutions were deposited onto the specimens using a dropper pipette and the water was evaporated by heating the samples on a hot plate up to about $200^{\circ} \mathrm{C}$. The specimens were recoated every 100 hours applying a salt deposition rate of $1.0 \mathrm{mg} \cdot \mathrm{cm}^{-2} \cdot 100 \mathrm{~h}^{-1}$. No washing of the samples prior to recoating was conducted. The specimens were weighed before and after coating with salt as well as before and after exposure using a Mettler model AG245 analytical balance. Mass change of the specimens was calculated taking into account the mass loss of the $\mathrm{Pt}-\mathrm{Rh}$ hooks. Corrosion products were characterized using a field emission gun scanning electron microscope (FEG-SEM) equipped with energy dispersive $x$-ray analysis (EDXA).

Table II: Chemical composition (at.\%) of the alloys. Dopant concentrations were determined by inductively-coupled plasma analysis. Sulfur and oxygen contents were determined by combustion analysis. The level of detectability is 4ppma.

\begin{tabular}{lcccc}
\hline Alloys & René N5 & NiCoCrAlY & NiCrAlY & $\beta$-NiAl+Hf \\
\hline $\mathrm{Ni}$ & 64.85 & 40.38 & 70.61 & 48.84 \\
$\mathrm{Al}$ & 13.88 & 23.49 & 19.42 & 51.05 \\
$\mathrm{Fe}$ & 0.08 & 0.02 & & \\
$\mathrm{Cr}$ & 7.79 & 17.43 & 9.89 & $<0.01$ \\
$\mathrm{Si}$ & 0.15 & $<0.01$ & & \\
$\mathrm{Co}$ & 7.28 & 18.48 & & \\
Other & $2.11 \mathrm{Ta}$ & $0.01 \mathrm{Ti}$ & & \\
& $1.61 \mathrm{~W}$ & & & \\
& $1.02 \mathrm{Re}$ & & & \\
Dopant & $0.90 \mathrm{Mo}$ & & & \\
& $0.05 \mathrm{Hf}$ & $0.15 \mathrm{Y}$ & $0.04 \mathrm{Y}$ & $0.05 \mathrm{Hf}$ \\
$\mathrm{C}$ & $0.003 \mathrm{Y}$ & $<0.01 \mathrm{Zr}$ & & \\
$\mathrm{O}$ & $0.003 \mathrm{Zr}$ & $<0.01 \mathrm{Hf}$ & & \\
$\mathrm{N}$ & 0.25 & 0.04 & 0.04 & \\
$\mathrm{~S}$ (ppma) & 0.005 & 0.006 & & \\
\hline
\end{tabular}


Table III: Salt chemistries [in $w t . \%$ ] and respective $\mathrm{K} / \mathrm{Na}$ atomic ratios.

\begin{tabular}{cccccc}
\hline Designation & $\mathrm{K}_{2} \mathrm{SO}_{4}$ & $\mathrm{Na}_{2} \mathrm{SO}_{4}$ & $\mathrm{CaSO}_{4}$ & $\mathrm{MgSO}_{4}$ & $\mathrm{~K} / \mathrm{Na}$ atomic ratio \\
\hline salt 1 & - & 100 & - & - & 0 \\
salt 2 & 100 & - & - & - & $\propto$ \\
salt 3 & 75 & 25 & - & - & 2.40 \\
salt 4 & 50 & 50 & - & - & 0.82 \\
salt 5 & 25 & 75 & - & - & 0.27 \\
salt 6 & 10 & 90 & - & - & 0.09 \\
salt 7 & 7 & 93 & - & - & 0.06 \\
salt 8 & 7 & 55 & 15 & 23 & 0.10 \\
\hline
\end{tabular}

\section{Results and Discussion}

\section{$\underline{\mathrm{Na}}_{2} \underline{\mathrm{SO}}_{4}$ Deposits - Conventional Type I Hot Corrosion}

Results of the thermal cycling tests involving $1 \mathrm{~h}$ cycles at $950^{\circ} \mathrm{C}$ for different $\mathrm{Na}_{2} \mathrm{SO}_{4}$-coated and uncoated alloys are shown in Fig. 1. Uncoated René $\mathrm{N} 5$ and $\beta$ $\mathrm{NiAl}$ exhibited low mass gains up to 350 cycles, although the oxide scales consisted mainly of transient alumina rather than $\alpha$-alumina (alumina modifications other than $\alpha$-alumina will be designated as transient alumina in the following).

Unlike bare René N5, $\mathrm{Na}_{2} \mathrm{SO}_{4}$-coated René N5 started to continuously lose mass after an initial $20 \mathrm{~h}$ period of mass gain. Repeated spallation of scale during cooling led to considerable consumption of the alloy (Fig. 2a). The oxide scale formed during testing was tinted green and blue indicating the formation of $\mathrm{Ni}$ - and $\mathrm{Cr}$ rich oxides rather than $\mathrm{Al}_{2} \mathrm{O}_{3}$. SEM investigations revealed that the specimen surface was mainly covered by spinel phases (Fig. 3a) and only in some small areas
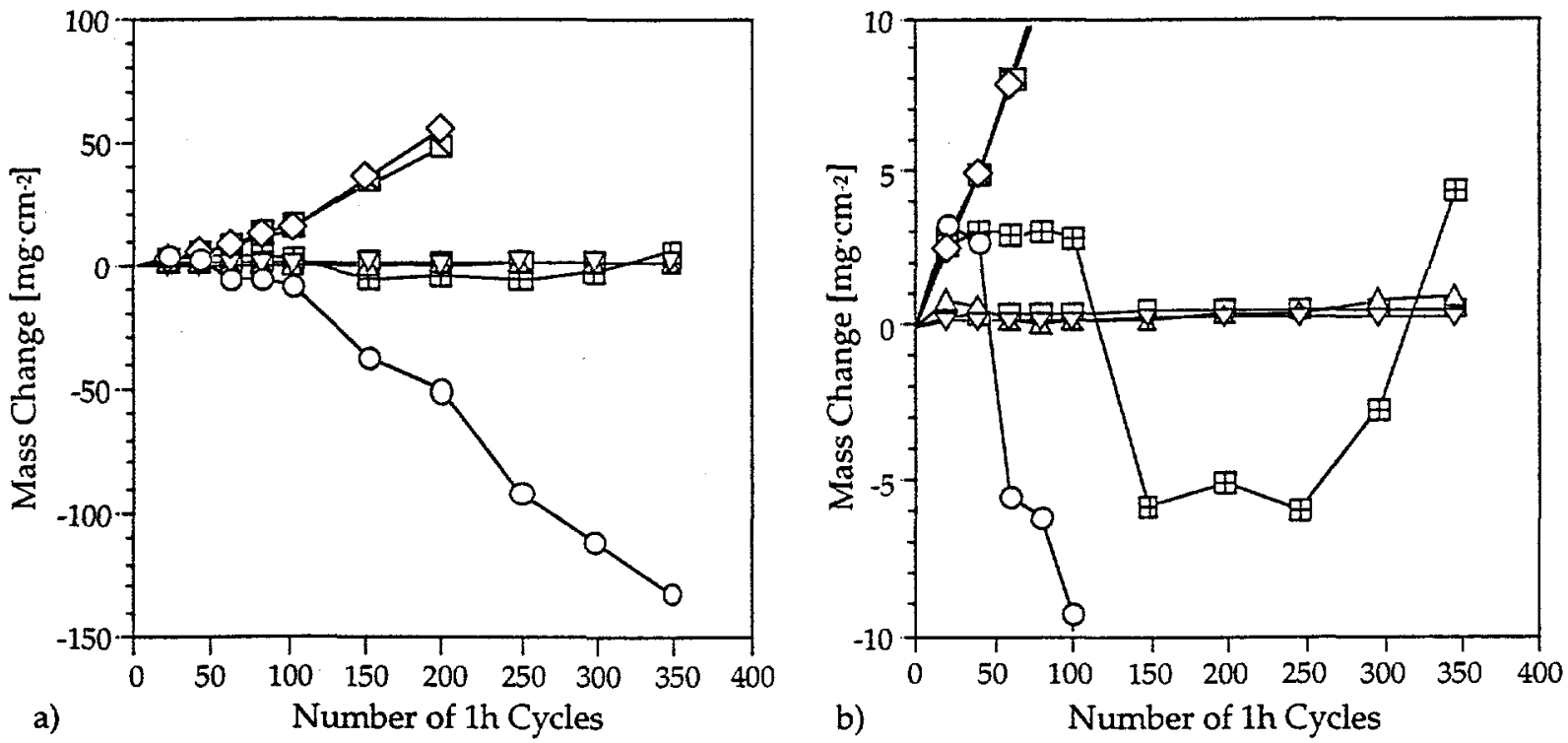

\begin{tabular}{|c|c|c|}
\hline $\begin{array}{l}-\nabla-\text { René N5, no hot corrosion } \\
-\square-\text { René N5 }\end{array}$ & $\begin{array}{l}-\square-\mathrm{NiAl}+\mathrm{Hf} \text {, no hot corrosion } \\
-\mathrm{D}-\mathrm{NiAl}+\mathrm{Hf} \text {, preoxidized }\end{array}$ & 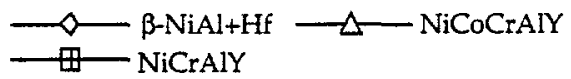 \\
\hline
\end{tabular}

Figure 1: Cyclic oxidation data at $950^{\circ} \mathrm{C}$ for various alloys during 1-h cycles: Samples were coated with $1.0 \mathrm{mg} \cdot \mathrm{cm}^{-2} \mathrm{Na}_{2} \mathrm{SO}_{4}$ prior to testing and were recoated every $100 \mathrm{~h}$. For $\beta-\mathrm{NiAl}+\mathrm{Hf}$ tests were stopped after $200 \mathrm{~h}$ since the samples started to disintegrate. An expanded y axis is shown in (b). 


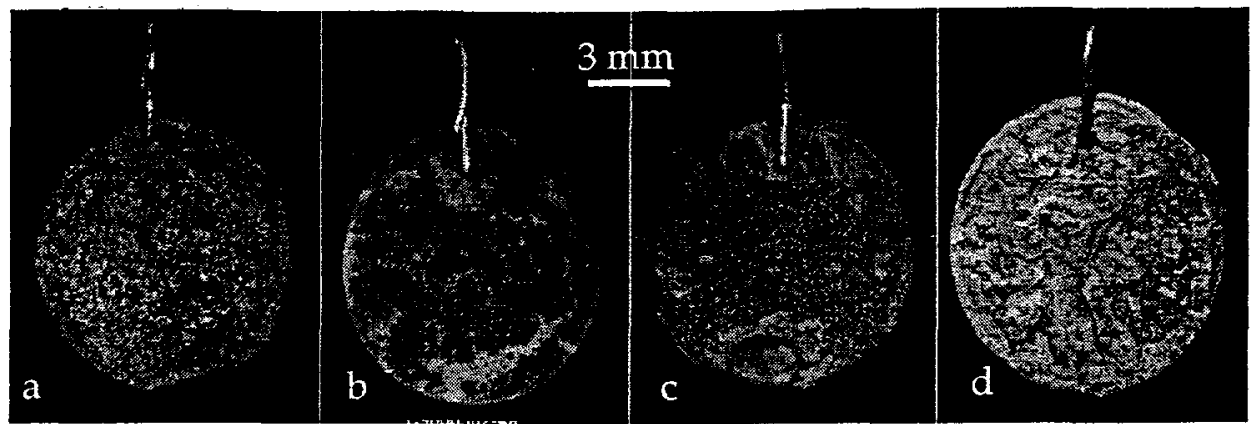

Figure 2: Macroscopic appearance of selected specimens coated with $\mathrm{Na}_{2} \mathrm{SO}_{4}$ after 1-h cyclic hot corrosion testing at $950^{\circ} \mathrm{C}$; a: René $\mathrm{N} 5$ after $350 \mathrm{~h}, \mathrm{~b}$ : $\mathrm{NiCoCrAlY}$ after $350 \mathrm{~h}$, lighter areas are alumina, darker areas are spinel phase, c: NiCrAlY after $350 \mathrm{~h}$, and $\mathrm{d}$ : $\beta-\mathrm{NiAl}+\mathrm{Hf}$ (preoxidized) after $200 \mathrm{~h}$.

were remnants of alumina scale present (Fig. 3b). It is believed that the alumina in the outer scale was formed by precipitation from the salt, after the mechanism indicated by Rapp [7], rather than being a relic of the initially-formed $\mathrm{Al}_{2} \mathrm{O}_{3}$ scale.

Although little mass loss was observed, the NiCoCrAlY alloy revealed essentially the same reaction as René N5 during thermal cycling (Fig. 1b). After a short period of mass gain the oxide scale on the NiCoCrAIY alloy started to spall. As on René N5, mainly spinel phase formed on the NiCoCrAlY alloy during testing but larger fractions of alumina remnants were observed (Fig. 2b).

The NiCrAIY alloy formed a reasonably adherent oxide scale during the initial 100 , 1h cycles (Fig. 1b), but considerable spallation of part of the scale (Fig. 2c) was measured after 150 cycles. However, the degree of mass loss was moderate compared with that on René N5. The oxide scale that reformed after spallation provided a fair amount of protection, but after 300 and 350 cycles, considerable mass gain occurred.

$\beta-\mathrm{NiAl}+\mathrm{Hf}$, which is considered to be an 'ideal' alumina former [19] because it readily forms a very adherent slow-growing $\alpha$-alumina scale, exhibited very poor resistance to attack by $\mathrm{Na}_{2} \mathrm{SO}_{4}$ (Fig.1). Despite its large reservoir of $\mathrm{Al}$, and the fact that the salt was present on the surface only intermittently, parts of the specimens underwent breakaway oxidation after a few cycles. After 200, $1 \mathrm{~h}$ cycles the
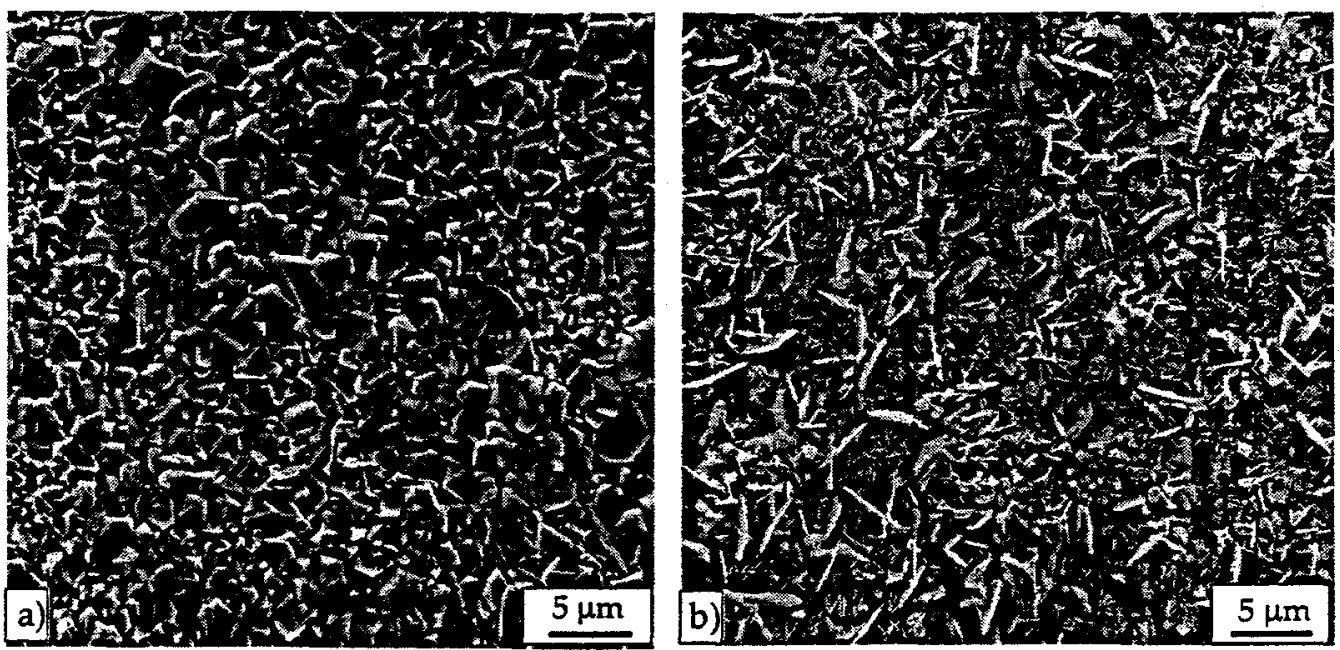

Figure 3: SEM secondary electron images of surface of René $\mathrm{N} 5$ coated with $\mathrm{Na}_{2} \mathrm{SO}_{4}$ after 350, 1 - $\mathrm{h}$ cycles at $950^{\circ} \mathrm{C}$. The surface is mainly covered by spinel phase (a), but some areas also contain transient alumina (b). 

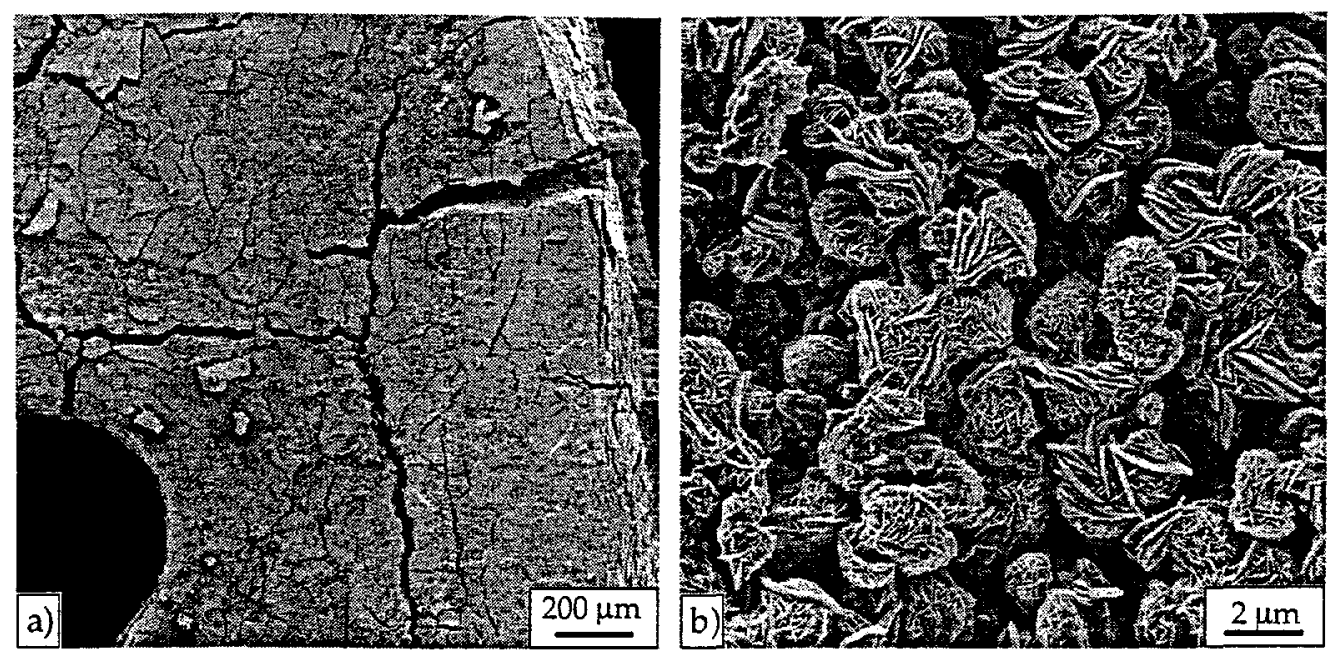

Figure 4: SEM secondary electron images of the surface of $\beta-\mathrm{NiAl}+\mathrm{Hf}$ coated with $\mathrm{Na}_{2} \mathrm{SO}_{4}$ after $200,1-\mathrm{h}$ cycles at $950^{\circ} \mathrm{C}$. The sample started to disintegrate after this period (a). Transient alumina platelets form spherical oxide particles (b).

specimen started to disintegrate (Fig. 2d). The heavily cracked oxide scale consisted mainly of platelets of transient alumina which were associated with spherical particles (Fig. 4). Long cracks along the grain boundaries of the alloy were observed after $150 \mathrm{~h}$ which propagated through the whole specimen thickness. Although those areas with a thick oxide scale were tinted greenish, EDXA detected no elements other than oxygen and aluminum, indicating that the scale was essentially alumina.

Further, preoxidation prior to corrosion testing to form a continuous $\alpha$-alumina scale did not improve the corrosion resistance of $\beta-\mathrm{NiAl}+\mathrm{Hf}$ at all. Rapid degradation and mass gain were also observed for the preoxidized specimen (Figs. 1 and 2d). After 200 cycles the scale was predominantly alumina with a platelet morphology indicative of a transient alumina (Fig. 5a) and occasionally spinel phase was formed (Fig. 5b), suggesting that dissolution of the original alumina scale and underlying alloy had occurred. No remnants of the initial
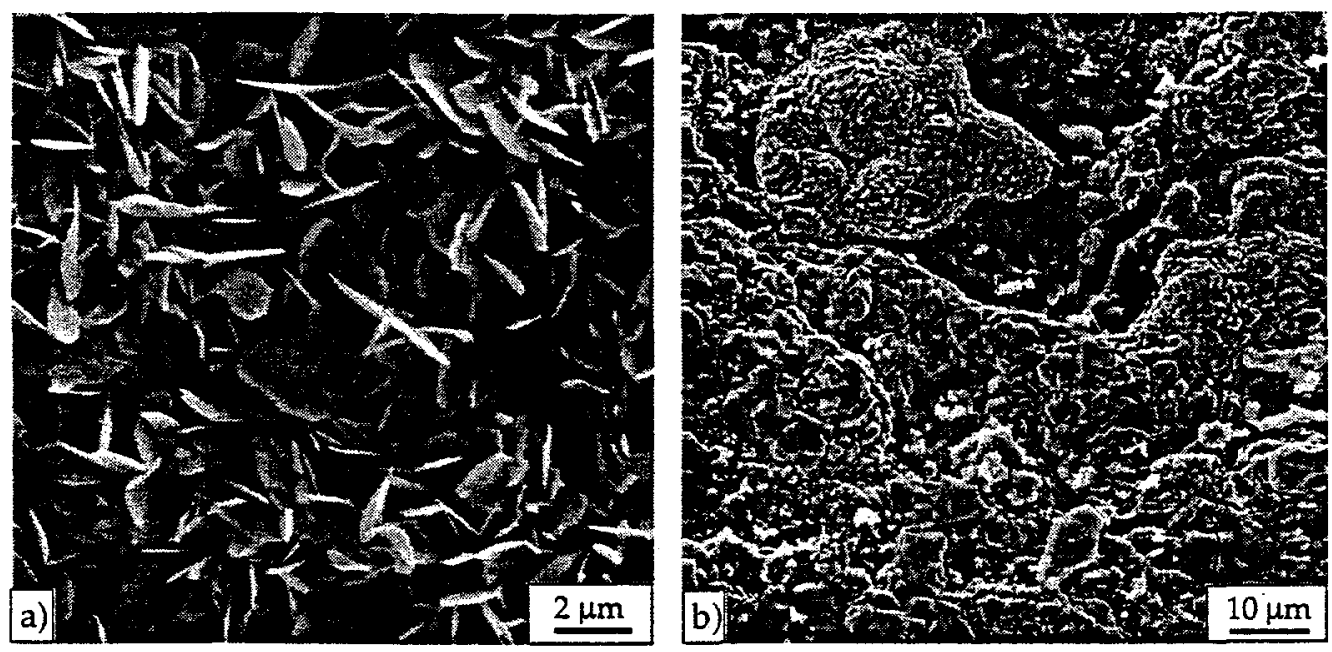

Figure 5: SEM secondary electron image of the surface of preoxidized $\beta-\mathrm{NiAl}+\mathrm{Hf}$ coated with $\mathrm{Na}_{2} \mathrm{SO}_{4}$ after $200,1-\mathrm{h}$ cycles at $950^{\circ} \mathrm{C}$. The sample started to disintegrate after this period. Despite formation of $\alpha$-alumina during preoxidation the surface is covered by oxide platelets indicative of transient alumina formation after hot corrosion testing (a). In some areas spinel phase forms (b). 
preoxidized alumina layer were observed. It is quite obvious from these results that the large aluminum reservoir and the potential to reform a damaged, initially protective scale was not sufficient to provide protection against $\mathrm{Na}_{2} \mathrm{SO}_{4}$-induced hot corrosion in this test. The implications of these observations are that, as expected, in all cases any protective alumina scale was rapidly dissolved in the molten salt. Following conventional understanding of hot corrosion mechanisms, the extent of subsequent corrosion was dependent on the basicity of the salt after dissolution of elements from the substrate. In general, increasing the alloy $\mathrm{Cr}$ level correlated with decreased extent of attack, although all the alloys tested were corroded. This suggests that dissolution of $\mathrm{Cr}$ was the dominant factor in maintaining a relatively low solubility of alumina in the salt, although the other effect of $\mathrm{Cr}$ dissolution in forming alleotropes and so speeding up the removal of the salt by evaporation probably played a role. A further implication is that, for these alloys, resistance to hot corrosion was realized only after any protective scale had been breached, and elements from the substrate entered the salt.

\section{NiCoCrAlY Exposed to a Range of Salt Compositions}

Results of thermal cycling of the NiCoCrAlY cast alloy coated with different salt compositions for $1 \mathrm{~h}$ at $950^{\circ} \mathrm{C}$ are summarized in Fig. 6. Note that the y-axis is quite different from that in Fig. 1. In the initial period of exposure the mass gains of all specimens were quite similar and reasonably low suggesting that a protective alumina scale had formed on all specimens. During this period the samples were covered with an adherent gray oxide scale indicative of alumina. However, the mass gains increased after 20-40h of exposure for those specimens which were coated with the highest $\mathrm{Na}_{2} \mathrm{SO}_{4}$ concentration (salt 1 and 7) or that with the salt mixture containing $\mathrm{MgSO}_{4}$ and $\mathrm{CaSO}_{4}$. However, after this short period of rapid mass gain, the rates decreased until they exhibited the average mass gain of the remaining specimens. With increasing time of exposure the scales on all specimens started to : cally develop blue-tinted oxides which were identified after testing as spinel pl..ses. After about $150 \mathrm{~h}$, the mass gain started to increase more rapidly depending : - the composition of the salt deposited onto the specimens.
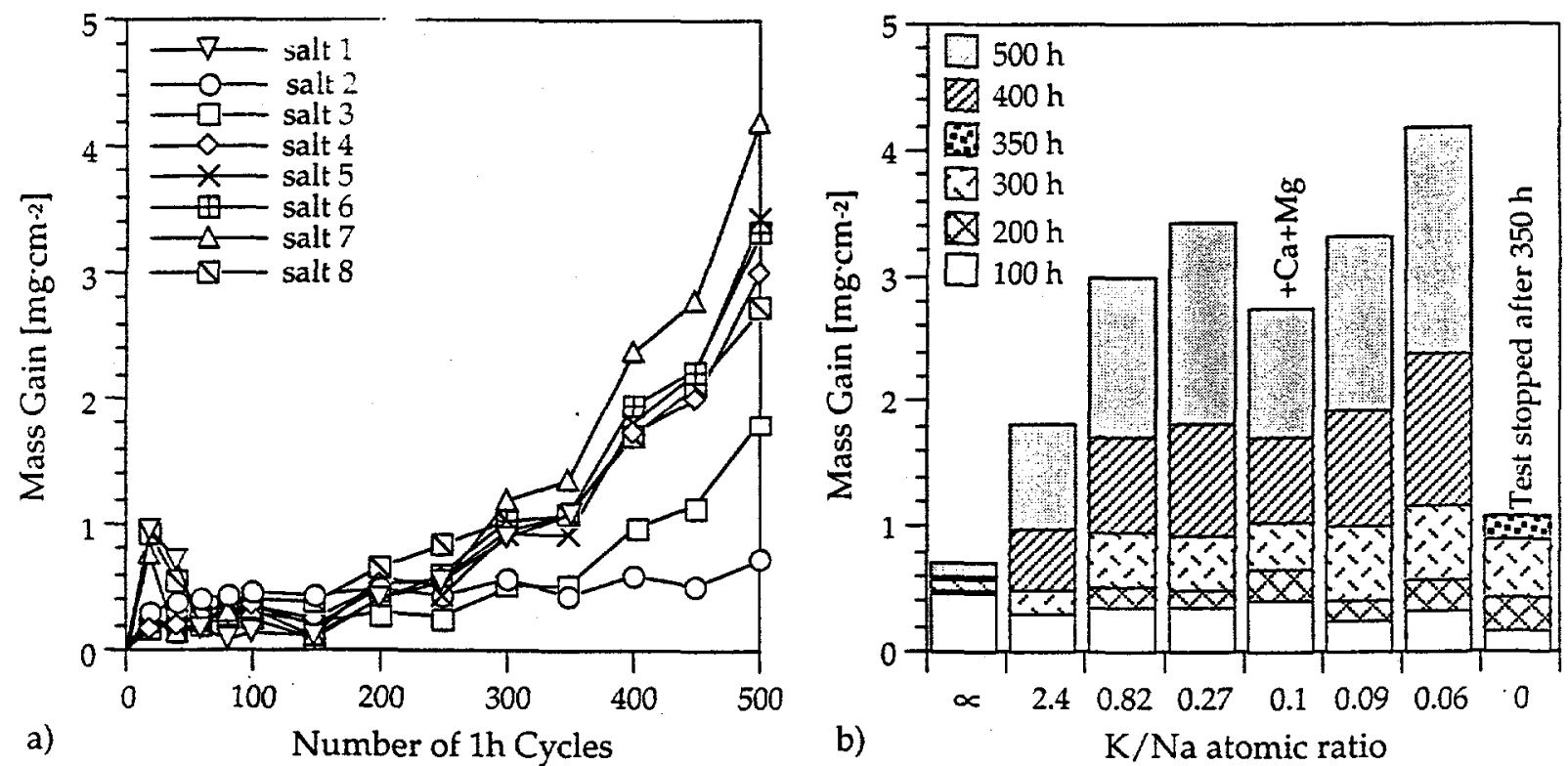

Figure 6: a) Cyclic oxidation data at $950^{\circ} \mathrm{C}$ for cast NiCoCrAlY during 1-h cycles. All samples were coated with $1.0 \mathrm{mg} \cdot \mathrm{cm}^{-2}$ salt prior to testing and recoated every $100 \mathrm{~h}$; b) Mass gain vs. $\mathrm{K} / \mathrm{Na}$ atomic ratio obtained from data in a). Note that the test for the sample coated with pure $\mathrm{Na}_{2} \mathrm{SO}_{4}$ was stopped after 350 cycles. 
The spinel phases were observed to grow at the expense of alumina on all specimens and after $500 \mathrm{~h}$ the spinels were the only phases present on the surfaces, with no alumina observed by SEM/EDXA in plan view.

Compared to most of the $\mathrm{Na}_{2} \mathrm{SO}_{4}$-containing salt deposits, pure $\mathrm{K}_{2} \mathrm{SO}_{4}$ (salt 2) and the mixture of $75 \% \mathrm{~K}_{2} \mathrm{SO}_{4} / 25 \% \mathrm{Na}_{2} \mathrm{SO}_{4}$ (salt 3) resulted in less weight gain. In the case of pure $\mathrm{K}_{2} \mathrm{SO}_{4}$, the oxide scale provided reasonable protection up to $500 \mathrm{~h}$ at $950^{\circ} \mathrm{C}$ (Fig. 6a) although no alumina was observed on the specimen surface. As for all the other salts, the $75 \% \mathrm{~K}_{2} \mathrm{SO}_{4} / 25 \% \mathrm{Na}_{2} \mathrm{SO}_{4}$ mixture caused an increase in corrosion rate after an incubation period of about $250 \mathrm{~h}$, but the overall mass gain was lower than for the other salts. Figure $6 \mathrm{~b}$ shows mass gain as a function of the $\mathrm{K} / \mathrm{Na}$ atomic ratio of the salts. The general trend of the data suggested that $\mathrm{Na}_{2} \mathrm{SO}_{4}$ was the key driver for corrosion of the NiCoCrAlY alloy. The more sodium the salt contained the more severe was the attack. For example, $25 \mathrm{wt} \% \mathrm{Na}_{2} \mathrm{SO}_{4}$ more than doubled the mass gain after $500 \mathrm{~h}$ compared with pure $\mathrm{K}_{2} \mathrm{SO}_{4}$. In the $\mathrm{K} / \mathrm{Na}$ ratio range between 0.82 and 0.09 the mass gain was only slightly affected but was nevertheless high and increased further when the $\mathrm{K}_{2} \mathrm{SO}_{4}$ content was reduced to $7 \mathrm{wt} . \%$. These results are in general accordance with earlier findings of Deadmore and Lowell [20] who reported an insensitivity of the $\mathrm{K} / \mathrm{Na}$ ratio for corrosion of IN-100, MAR M-509, and IN-792 tested in a burner rig at $900^{\circ} \mathrm{C}$ for $100 \mathrm{~h}$, except for zero sodium. In addition, the present results suggest that there might be two thresholds with respect to the severity of corrosion. Starting at $100 \%$ potassium, corrosion strongly increased from the addition of sodium in excess of $25 \mathrm{wt} . \%$ $(\mathrm{K} / \mathrm{Na}=2.4)$. Although it was beyond the scope of this study to define the exact limit for this first threshold, it is expected that even lower sodium contents might increase the intensity of corrosion compared with pure potassium sulfate. Another threshold seemed to occur at a $\mathrm{K} / \mathrm{Na}$ ratio of about 0.06 , where attack again started to accelerate. It is apparent that the present results provided no evidence of a simple additive effect of combining sodium and potassium on hot corrosion of the NiCoCrAlY coating. On the contrary, although causing considerable dissolution of the alumina scale, the addition of potassium sulfate led to reduced corrosion compared with pure sodium sulfate. Magnesium and calcium sulfates which were found in deposits on turbine blades [15] slightly decreased the corrosion attack but
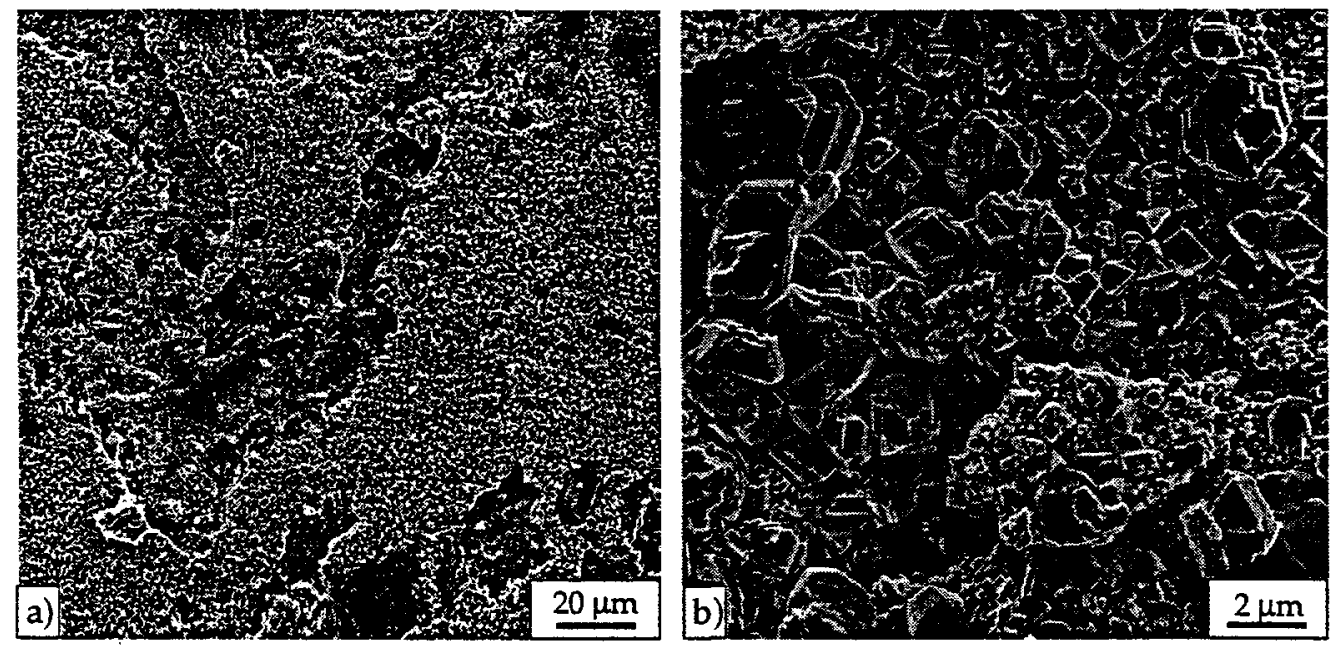

Figure 7: SEM secondary electron image of the surface of NiCoCrAlY after 500h exposure at $950^{\circ} \mathrm{C}$. Although the oxide scale on the specimen coated with $100 \% \mathrm{~K}_{2} \mathrm{SO}_{4}$ (salt 2 ) is relatively smooth partial spallation of the surface layer is clearly visible (a). Specimens coated with $7 \% \mathrm{~K}_{2} \mathrm{SO}_{4} / 93 \% \mathrm{Na}_{2} \mathrm{SO}_{4}$ formed locally somewhat larger spinel crystals formed thus causing a rougher surface (b). In general, the presence of $\mathrm{K}_{2} \mathrm{SO}_{4}$ seemed to promote formation of a smaller spinel grain size. 
the level was still considered to be high. It should be noted that accelerated attack of the NiCoCrAlY afloy was only measurable after an incubation period of about 150-250h, depending on the composition of the salt deposits. During the incubation period, differences in the corrosion resistance of the NiCoCrAlY alloy against various salts were less obvious. After the incubation period, accelerated corrosion behavior appeared to be triggered by the consumption of the protective alumina scale. The corrosion mechanism may change once the incubation period ends.

Although all specimens were nearly identical visually after $500 \mathrm{~h}$ testing, SEM investigations revealed that the less corroded specimens retained a smoother surface (Fig. 7a). The outermost oxide scales of these specimens consisted of finegrained spinel crystals which partly spalled (darker areas in Fig. 7a). With increasing sodium fraction in the salt, coarser spinel crystals locally formed, and these had a stronger tendency to spall. However, as the mass gain was higher for these specimens, partial oxide scale spallation must have been overcompensated by rapid dissolution of substrate elements to form the spinel phases.

\section{Conclusions}

The simplified test conditions used in this study were found to induce Type I hot corrosion of Ni-base alloys during thermal cycling at $950^{\circ} \mathrm{C}$. Single crystal alloy René N5 and the MCrAl-based coating alloys suffered mass loss due to the formation of a fine-grained, voluminous alumina-containing scale, typical of oxide dissolved and re-precipitated from a molten salt, and subsequent scale spallation. The extent of loss from the model $\mathrm{MCrAl}$ coating alloys was less for the higher-Cr alloy. Although considered an 'ideal' alumina former in air or pure oxygen, model alloy $\beta-\mathrm{NiAl}+\mathrm{Hf}$ suffered extensive attack from hot corrosion despite its large Al reservoir. The normally protective alumina scale was converted into voluminous, fine-grained, non-protective alumina-rich scale after only a few cycles. A role of $\mathrm{Cr}$ in preventing rapid degradation of the alumina scale was indicated by results with cast NiCrAlY and NiCoCrAlY alloys. These exhibited better hot corrosion resistance but were still significantly attacked.

These results not only demonstrate the well-known beneficial effect of $\mathrm{Cr}$ on resistance to Type I hot corrosion, but also indicate that in these nominally protective alumina scale-forming alloys, resistance to hot corrosion occurs only after the protective scale has been locally dissolved and an area of (probably) voluminous scale has been formed. This observation has serious implications for the integrity of TBCs, where such alloys are used as bond coatings.

In the mixed salts intended to provide an initial screening of the relative effects of $\mathrm{K}$ versus $\mathrm{Na}$, sodium sulfate rather than potassium sulfate was found to be the principal factor in corrosion of the NiCoCrAlY alloy. In a medium range corrosion was insensitive to the $\mathrm{K} / \mathrm{Na}$ ratio of the salt deposit, but the attack was accelerated when only $7 \mathrm{wt}$. $\% \mathrm{~K}_{2} \mathrm{SO}_{4}$ was present in the salt, the remainder being $\mathrm{Na}_{2} \mathrm{SO}_{4}$. A minimum in the rate of attack was found with pure $\mathrm{K}_{2} \mathrm{SO}_{4}$. However, there was no evidence of a simple additive effect of combining sodium and potassium on hot corrosion of the NiCoCrAlY alloy. Further research will be focused on the form of hot corrosion caused by deposits of alkali metal salts having an excess of alkali compared to sulfur, which is thought to be more representative of deposits from biomass-derived fuels. 


\section{Acknowledgments}

Research sponsored by the U.S. Department of Energy, Assistant Secretary for Energy Efficiency and Renewable Energy, Office of Industrial Technologies, as part of the Advanced Turbine Systems Program under contract DE-AC05-960R22464 with Lockheed Martin Energy Research Corporation, and the German Aerospace Center. S. Watson and B. Nagaraj of GE Aircraft Engines provided René N5 specimens. J.R. DiStefano and P.F. Tortorelli at ORNL provided comments on the manuscript.

\section{References}

[1] C.M. Kinoshita et al., "Power Generation Potential of Biomass Gasification Systems," Journal of Energy Engineering, (December) (1997), 88-99.

[2] M. DeCorso et al., "Coal/Biomass Fuels and the Gas Turbine: Utilization of Solid Fuels and their Derivatives," ASME Paper No. 96-GT-76, (1996).

[3] W.P. Parks et al., "The Advanced Turbine Systems Program in the U.S.A.", in: Materials for Advanced Power Engineering, Vol. III, ed. J. Lecomte-Beckers et al. (Forschungszentrum Jülich/Reihe Energietechnik/Energy Technology, 1998), 1789-1805.

[4] M.A. Paisley and D. Anson, "Biomass Gasification for Gas Turbine-Bases Power Generation," Transactions of the ASME, 120 (1998), 284-288.

[5] P. Hancock and M. Malik, "Coating Systems and Technologies for Gas Turbine Applications", in: Materials for Advanced Power Engineering, ed. D. Coutsouradis et al. (The Netherlands: Kluwer Academic Publishers, 1994), 685-704.

[6] N.S. Bornstein, "Reviewing Sulfidation Corrosion-Yesterday and Today," JOM, 48 (2) (1996), 37-39.

[7] R.A. Rapp, "Chemistry and Electrochemistry of Hot Corrosion of Metals," Materials Science and Engineering, 87 (1987), 319-327.

[8] V.Srinivasan, "High-Temperature Corrosion and Erosion in Gas Turbine Engines-Where do we Stand?," LOM, (December) (1994), 34.

[9] J.L. Smialek, F.A. Archer, and R.G. Garlick, "Turbine Airfoil Degradation in the Persian Gulf War," LOM, (December) (1994), 39-41.

[10] P. Hancock, "The Use of Laboratory and Rig Tests to Simulate Gas Turbine Corrosion Problems," Corrosion Science, 22 (1) (1982), 51-65.

[11] N.J. Simms and J.E. Oakey, "Materials Issues in Coal-Fired Combined Cycle Power Generation Systems: Laboratory versus Plant Testing," Materials Science Forum, 251-254 (1997), 543-550.

[12] I.G. Wright, C. Leyens, and B.A. Pint, "An Analysis of the Potential Corrosion Threat to Gas Turbines Fueled by the Products of Biomass Gasification," submitted to the ASME Gas Turbine Conference.

[13] M.A. DeCrescente and N.S. Bornstein, "Formation and Reactivity Thermodynamics of Sodium Sulfate with Gas Turbine Alloys," Corrosion, 24 (1968), 127-133.

[14] C.G. McCreath, "Hot Corrosion Site Environment in Gas Turbines," Materials Science and Technology, 3 (1987), 494-500.

[15] N.S. Bornstein and W.P. Allen, "The Chemistry of Sulfidation Corrosion-Revisited," Materials Science Forum, 251-254 (1997), 127-134.

[16] J.G. Olsson et al., "Alkali Metal Emission from Filter Ash and Fluidized Bed Material from PFB Gasification of Biomass," Energy and Fuels, 12 (1998), 626-630.

[17] D.C. Dayton, R.J. French, and T.A. Milne, "Direct Observation of Alkali Vapor Release during Biomass Combustion and Gasification. 1. Application of Molecular Beam/Mass Spectrometry to Switchgrass Combustion," Energy and Fuels, 9 (1995), 855-865.

[18] E. Kurkela: Formation and Removal of Biomass-Derived Contaminants in Fluidized-Bed Gasification Processes, VTT Publications No. 287 (1996).

[19] B.A. Pint et al., "Substrate and Bond Coat Compositions: Factors Affecting Alumina Scale Adhesion," Materials Science and Engineering, A245 (1998), 201-211.

[20] D.L. Deadmore and C.E. Lowell: Effects of Impurities in Coal-Derived Liquids on Accelerated Hot Corrosion of Superalloys, DOE/NASA 2593/13 (1980). 